\title{
Recovered memory: the nature of the controversy
}

\author{
Sydney Brandon
}

Professional awareness of the reality and frequency of sexual abuse of children was raised during the early $1980 \mathrm{~s}$. This was gradually followed by an increasing awareness of the frequency of extra-familial abuse and of the fact that abusers, even those who initially come to light through abuse within the family, usually had multiple victims. The difference between abusive fathers and other paedophiles became less evident.

The American psychoanalyst, psychiatrist and feminist Judith Herman (1987) talked of massive 'repression' in adult life of memories of childhood sexual abuse (CSA) and of the setting-up of an informal network of private practice therapists who were searching for such memories in adults. Over the next few years there were many accounts of 'massive repression' and of recovered memories, mostly published in the lay press.

In 1988 two American teachers of creative writing, Ellen Bass and Laura Davis, published The Courage to Heal, which was to become the bible of what has been described as the recovered memory movement. Some talked of the recovered memory industry and Crews (1997) has written a comprehensive account of the 'memory wars.'

American Psychiatric Association meetings became increasingly concerned with a revival of interest in multiple personality disorder and an increasing conviction, mostly in fringe groups, that massive repression of memories of CSA was responsible for much psychiatric morbidity and particularly for multiple personality disorder or dissociation identity disorder. Gradually, however, the recovered memory debate moved centre stage, becoming a prominent feature of every meeting and characterised by angry and vituperative debate with increasing polarisation between believers and non-believers. A curious feature of the debate was the linking of recovered memories with alien abduction and multiple personality disorder. Jacobs, a historian, published Secret Life: Firsthand Accounts of UFO Abductions (1992) and in 1994 John Mack, a Harvard professor of psychiatry, published the book Abduction: Human Encounters with Aliens, which became a best-seller and described abduction into spaceships where aliens carried out experiments including sexual exploration and impregnation. The advocates of massive repression described how some of those abused by aliens needed 'recovered memory therapy' to enable them to recall accurately what had happened to them during blank periods which they could not otherwise account for. Enthusiasts for the diagnosis of multiple personality disorder or dissociation identity disorder told us that these states usually had their origins in repressed CSA. They presented dramatic videos of 'multiples' who reported such abuse but the videos were most striking for the way in which they showed how the therapist led the subject remorselessly towards the development of 'alter' personalities. Reports were also appearing in the lay press of those who had recovered memories of sexual abuse initiating prosecution of their alleged assailants; one father was convicted of murder on the basis of such recovered memories, though the latter conviction was dismissed on appeal.

In 1992 the False Memory Syndrome Foundation was set up in Philadelphia and soon had 18000 families as members. The British False Memory Society, with 900 families, was set up in 1993.

The unseemly scenes at the American Psychiatric Association and the widespread public debate seemed to be leading to a devaluation of psychotherapy and (despite the fact that most of the therapists were not psychiatrists or even mental health professionals) to be bringing psychiatry itself into disrepute. As a result of this the President of the College, in anticipation of the controversy escalating on this side of the Atlantic, set up a working group to examine the issues and give clear guidelines for practice to College members.

The Working Group on Reported Recovered Memories of Child Sexual Abuse was set up in May 1995 and produced its report and guidelines in 1996. The guidelines were published in October 1997 (Royal College of Psychiatrists, 1997) and the report on which these were based was published in April 1998 (Brandon et al, 1998).

The authors reject the concept of massive repression and failed to find convincing evidence that repeated sexual abuse in childhood is ever 
completely forgotten. Many who have been abused have suffered for years from psychosexual or relationship problems but their troubles lie in being unable to forget the trauma rather than in repressing it. They may try to push it from their mind, to avoid thinking or talking about it and they may have kept the memories and the pain entirely to themselves, denying to others that it ever occurred. Sometimes a sexual relationship, marriage or the birth of a child may make the secrecy unbearable and they then reveal what happened to their partner or others.

Particularly disturbing are the beliefs of those employing recovered memory therapy and the methods they use. Some therapists specialising in recovered memory therapy told their clients that 'intuitively' or perhaps as a result of checklists they were convinced that the client had been abused as a child and that they needed to recover those memories in order to achieve recovery. They were encouraged to search for possible memories of abuse or to assume that they had been abused and to try, over as long as a year, to 'think themselves into abuse'. One patient reported 'I would walk around saying "My family abused me". I had to say it a lot to really believe it. My first year and a half was spent just accepting the fact that I had been abused'. Other doubters were encouraged to join 'survivor groups' where they were sometimes encouraged to adopt the group norm, that is that they too were survivors. Others were subjected to more exotic 'treatments' such as repeated hypnosis or 'age regression' in which they infallibly regressed not only to the age at which the abuse occurred but to the actual event.

It is not surprising that such zealots could induce in their clients false memories of events which had not occurred and in which they both believed with absolute and unshakeable conviction. What is more worrying is that some therapists who did not start off with these beliefs were convinced by colleagues of the validity of the idea that if you have adult relationship problems, you must have been abused as a child. Sometimes, their clients had already read Bass \& Davis, watched TV exposés or joined survivor groups and so were already primed. Sadly, the evidence is that those who do 'recover' memories of abuse often are more rather than less distressed afterwards (Loftus, 1997).

There seems no room to doubt that false memories can occur or be created but it does not follow that all recovered memories are there- fore false. What can be done to reduce the risk of creating false memories is to maintain good standards of psychiatric practice. Psychiatrists must be aware that their own belief systems and expectations can unconsciously influence their patients to share those beliefs. Some recovered memory therapists unwittingly use strong suggestion to subtly move their clients to a particular 'discovery'.

There is a constant need to remind psychiatrists of the power they unwittingly exert over their patients, to urge them to exercise the greatest care not to lead or suggest, to be aware of their own preconceptions and expectations and to seek independent collateral histories wherever possible. Many psychiatric diagnostic errors result from failure to take a complete. systematic history and to interview an independent informant.

In summary, false memories of CSA do occur and can be created by therapists. The use of techniques such as hypnosis, drug-mediated interviews and regression therapy facilitate the development of false memories. Once created, such memories are held with unshakeable conviction, often as a direct result of the techniques used. Such developments are best avoided by continued good psychiatric practice.

\section{References}

BASS, E. \& DAVIS, L. (1988) The Courage to Heal. A Guide for Women Survivors of Child Sexual Abuse. New York: Harper and Row.

BRANDON, S., BOAKES, J., GLASER, D. et al (1998) Recovered memories of childhood sexual abuse. Implications for clinical practice. British Joumal of Psyhchiatry, 172. 296-307.

CREWS, F. (1997) The Memory Wars. London: Granta.

HERMAN. J. L. (1987) Father-Daughter Incest. Cambridge. MA. Harvard University Press.

JACOBS. D. (1992) Secret Life: Firsthand Accounts of UFO Abductions. New York: Simon and Schuster.

LOFTUS. E. (1997) Repressed memory accusations: Devastated families and devastated patients. Applied Cognitive Psychology, 11, 25-30.

MACK. J. E. (1994) Abduction. Human Encounters with Aliens. New York: Macmillan.

RoYAl COLLEGE OF PSYCHIATRISTS (1997) Reported recovered memorles of child sexual abuse. Recommendations for good practice and implications for training, continuing professional development and research. Psychiatric Bulletin. 21. 663-665.

Sydney Brandon, 19 Holmfield Road, Leicester LE2 1SD 